\title{
1. Introduction: classical liberalism and robust political economy
}

\section{INTRODUCTION}

Contemporary debates in political economy have been shaped by reactions towards 'neo-liberalism'. From reform of the welfare state to discussions over international trade and the environment, many commentators have discussed the apparent ascendancy of a belief in 'free markets' and the minimal state. The impression generated by such commentary is that following the collapse of the socialist project in Eastern Europe and elsewhere, opposition to neoliberalism, or classical liberalism as it should really be known, has been marginalised in the political landscape.

A cursory glance at the trajectory of public policy, however, reveals a different picture. While the 'privatisation' movement of recent years may have slowed the advance of post-war social democracy, many policy areas have exhibited a marked resistance to liberalisation or have seen a further expansion in the role of government. The financing and delivery of health and education remain, for example, the overwhelming preserve of governments in most liberal democracies with even minor attempts to introduce market forces making little headway. In the realm of international trade, continued adherence to agricultural protectionism and widespread support for financial aid as the key to securing prosperity in developing economies confirms a lingering attachment to interventionist principles. Environmental policy has proven even more resistant to classical liberal ideas with a massive growth of regulatory initiatives. And, as if this were not enough, the unprecedented scale of government activism that followed the 'financial crisis' of 2008 hardly suggests that the grip of 'market fundamentalism' has been particularly secure.

The speed with which governments have sought to expand their powers in response to the recent financial crisis reflects a longer-term drift of ideas and opinion that far from supporting classical liberal ideas has actively sought to undermine them. In economics, for example, the dominant neo-classical tradition provides increasingly sophisticated rationales for government interventions ranging from product regulation to environmental taxes. Political theorists meanwhile question the philosophical and moral assumptions of classical liberalism, arguing that many of these are based on a crude form of individualism 
which undermines norms of solidarity and distributive justice. If there is a dominant position in contemporary social science, therefore, it is characterised explicitly or implicitly by hostility to classical liberalism and support for 'social democracy' at the national and the international scale.

In view of these developments, this book aims to challenge many of the arguments levied against classical liberalism in contemporary political economy and to restate the case for a movement 'towards the minimal state'. The aim of the book is not to present a 'new' contribution to political economy per se, but to synthesise existing arguments within an analytical framework 'robust political economy' - that demonstrates the ongoing relevance of classical liberal principles to some of the most pressing questions of the day. In completing this task, the book draws on a range of literature from economics and political theory with a particular focus on 'comparative institutions' reasoning. This introductory chapter commences by setting out the principle of institutional 'robustness' on which comparative institutions analysis is based. It then outlines the case for classical liberalism as meeting the requirements of 'robust political economy'. The final section sketches the major challenges to the robustness of classical liberalism addressed in the chapters that follow.

\section{COMPARATIVE INSTITUTIONS ANALYSIS AND ROBUST POLITICAL ECONOMY}

Political economy is concerned primarily with the comparative performance of social and economic institutions. Human action always takes place in a specific institutional milieu and the conditions that people face under different institutions affect the character of their behaviour and the resultant social outcomes. Within this context, a 'robust' set of institutions may be defined as one that generates beneficial results even under the least favourable conditions (Leeson and Subrick, 2006). Such conditions may arise as a consequence of human imperfections. If people are 'perfect' or at least 'perfectible' then questions of comparative institutional analysis may cease to arise - one would expect beneficial outcomes irrespective of the institutional framework. If, however, people are 'imperfect' in a variety of ways, then questions of institutional robustness assume centre stage. Certain institutions may be better placed than others to withstand the stresses and strains wrought by the relevant human weaknesses.

In the context of institutional analysis there are two human imperfections that must be accounted for when considering the robustness of alternative regimes. The first of these is the 'knowledge problem'. Human beings are limited in their cognitive capacities and as a consequence even the most intel- 
ligent and far-sighted people are relatively ignorant of the society in which they are situated (Hayek, 1948a; Simon, 1957). Given the imperfections of human knowledge, the consequences of any particular action, either for the actors concerned or for the wider society, will at any given time remain uncertain. Robust institutions should therefore allow people to adapt to circumstances and conditions of which they are not directly aware, and under conditions of 'bounded rationality' must enable them to learn from mistakes and to improve the quality of their decisions over time.

The second human imperfection that must be accounted for is the possibility that people may act out of self-interested motivations (Ostrom, 2006). Actors may follow their own specific goals - material or non-material - rather than some notion of the 'common good' or the 'public interest'. People may not be willing to contribute towards the advancement of their fellows' interests unless they are able to gain some personal benefit from doing so. Incentives may matter, and as a consequence institutions must be judged on their capacity to channel potentially self-interested motivations in a way that generates beneficial outcomes at the societal level. The pursuit of self-interested behaviour under certain institutional conditions may lead to social and economic breakdown, but if institutions are structured in an appropriate manner then even those driven by the most egotistical of motives may act in a way that benefits the society of which they are part.

Given the human imperfections noted above, a robust political economy of institutions and decisions seeks answers to the following three questions:

- Which institutions perform best when people are not omniscient?

- Which institutions perform best when people are motivated by self interest?

- Which institutions perform best when people have limited knowledge and are prone to self-interested behaviour?

\section{CLASSICAL LIBERALISM AND ROBUST POLITICAL ECONOMY}

The classical liberal answer to the above questions is that the institutions of private or severally owned property, a market economy, and a limited government confined to the resolution of disputes between private parties, are best placed to meet the requirements of a robust regime.

Classical liberalism as it is understood in this book originates in the Scottish enlightenment of Adam Smith and David Hume and more recently is reflected in the work of Friedrich Hayek, Michael Oakeshott and James Buchanan. The fundamental organising principle of classical liberalism is 
freedom of association and disassociation. People must, according to this view, have the freedom to enter and exit from a variability of human arrangements. These need not exclude authoritarian or communitarian organisations which subscribe internally to 'illiberal' norms, but social actors must be able to leave any group which they have joined voluntarily or have been 'born into' on an involuntary basis. A classical liberal society, therefore, is one where there are multiple authorities and jurisdictions, none of which exercises a total, hierarchical form of power over the others (Kukathas, 2003). An important precondition for such an order is that ownership of property, though not necessarily equal, is widely dispersed between an array of individuals and voluntary associations.

The private or several ownership of property is recognised by classical liberals as a modus vivendi, necessary to cope with the reality of diverse human values. In conditions of limited rationality, the capacity to enter and leave a variety of human arrangements facilitates trial and error learning as people may observe the results that flow from different modes of life. Moreover, the space that private property affords people to experiment with their own favoured ends minimises conflict in conditions where people exhibit different views of the good life. When ownership of property is dispersed there is greater scope to enter voluntary agreements and contracts to secure one's own ends, without preventing other actors from seeking alternative partners with which to pursue theirs. When ownership of property is concentrated in a single centre, by contrast, those who control the relevant agency have the capacity to impose their particular ends on others. From a classical liberal perspective, given the limited nature of human rationality and the possibility of self-interested behaviour such systems are likely to promote conflict as individuals and groups may seek to control the ruling apparatus to implement their own particular vision.

Freedom of association and the observance of private or several property rights are also emphasised by classical liberalism because they permit the formation of what Hayek refers to as 'spontaneous orders' (Hayek, 1982, Part 1). 'Orders' of this nature exhibit patterns of coordination, but the regularities at issue are not the product of deliberate design by agents pursuing a unitary goal. Rather, they are 'emergent' phenomena that arise from the actions of a variety of dispersed agents each pursuing their own separate ends. For classical liberalism the advantages of such orders are threefold and exemplified in a market economy based on dispersed, though unequal ownership of property.

First, spontaneous orders are better placed to cope with conditions of imperfect knowledge and bounded rationality because they draw on and adapt to knowledge embedded in the multiple nodes that constitute them. In markets, for example, dispersed individuals and organisations make bids for property rights and contribute incrementally to the formation of prices that transmit 
their particular 'bit' of information to the resource owners with whom they trade. The latter may then adapt their behaviour in light of their own preferences and knowledge, and these adaptations may affect subsequent transactions with still other agents in a network of increasing complexity. The price signals that emerge from such a process prompt 'economising behaviour' and enable a degree of coordination that may not be achieved by a central coordinating authority. Under conditions of limited rationality and knowledge, such an authority could not be aware of all the relevant margins for adjustment that are scattered across a diversity of social actors (Hayek, 1948a, 1982).

A second advantage of spontaneous orders is that they allow for experimental evolution. The decentralised exchange of property rights in a market, for example, allows competing production and consumption ideas to be tested simultaneously. Should there be only one decision-making or 'planning' body then any errors are more likely to be systemic. Adaptation in a spontaneous order is also speedier than in a centralised or 'planned' equivalent - actors may learn from and imitate the most profitable models without approval from an overarching authority or majority. Market participants need not be aware of how or why their actions benefit themselves or their fellows in order for systemic improvements to arise. Entrepreneurial discoveries may result from pure chance rather than conscious deliberation. What matters is that production models that meet consumer demands make profits which signal the need for imitation, while loss-makers divert people away from the least promising lines (Alchian, 1959). Consumers meanwhile need not know why they find some products more satisfying than others. All they need do is 'exit' from suppliers they find least satisfactory in favour of those they find more so. In order to function effectively, therefore, the market 'system' requires little cognitive competence from any of its participants (Friedman, 2005).

The previous points refer to the robustness of spontaneous orders in overcoming the 'knowledge problem' and make no assumptions about human motivations - they do not, for example, assume that actors are, or should be, egoistic. A third advantage of such orders, however, is that they provide safeguards against the abuse of power where people do act out of self-interest. As David Hume and, more recently, James Buchanan have argued, people should be modelled 'as if they are knaves' - not because most are egoistic, but because institutional safeguards are needed to constrain a selfish minority (Buchanan, 1986). In the specific case of markets, the 'exit' option may allow people to escape from actors who offer inferior terms of cooperation. Although the distribution of wealth in a market economy is uneven, this inequality is dynamic as resources are continually shifted away from those who fail to put their property to the most valued uses. A system of private property rights provides incentives that may encourage even the most uncooperative or egotistical agents to act in a socially tolerable vein. Where property rights are 
well defined, the costs of decisions are effectively internalised - actors profit from decisions which benefit their fellows but must bear the costs of those that do not (Alchian and Demsetz, 1973).

These principles of institutional robustness are relevant not only in the context of 'economic' decision-making but also with respect to matters of distributive justice. From a classical liberal perspective, institutions that enable actors to impose a unitary conception of distribution on society are incompatible with a process of evolutionary learning and the principle of freedom of association. Under conditions of limited rationality there may be substantial disagreement over what constitutes a 'fair' distribution of income and wealth. The results of a classical liberal order cannot be considered 'just' or 'unjust' because they are not based on obedience to a unitary system of commands, but follow from the actions of people associating on the basis of many different distributive norms (Hayek, 1982). The defining character of a 'liberal' system of justice should, therefore, be one of 'ends-independence' it should not attempt to determine the justice of the results that follow from freedom of association, but should seek to resolve disputes when it is not clear where rights of ownership lie, or whether such rights have been breached. Seen in this light, all actors - even if they disagree about distributive justice have an interest in maintaining a framework that ensures stability of possessions, because it is the latter that enables people to live their lives without coming into permanent conflict with their fellows (Otteson, 2006). From a classical liberal perspective, no central authority may access the knowledge necessary to judge all of the factors that contribute to a particular distribution, and given the possibility of self-interested behaviour no such authority should be trusted to determine the 'just deserts' of others.

If robust institutions are those that cope best with human imperfections then so too must the process of institutional design. In a world of imperfect knowledge and limited benevolence people may err when devising institutional structures. A robust political economy should, therefore, allow for evolutionary learning and provide checks and balances at the meta-institutional level. Thus, while classical liberalism is a theory that claims universal validity in explaining the institutional types best placed to facilitate social coordination, it does not offer a blueprint towards achieving any one institutional form. The processes of evolutionary learning that occur within markets should be operative on multiple levels so that people can exit and enter competing and often overlapping institutional designs (Buchanan and Vanberg, 2002). The state, therefore, although a particularly powerful organisation should be just one of many other similar organisations, constrained in its powers by the existence of competitors.

It is important to specify in this context what a commitment to the 'minimal state' actually implies. The most significant point to emphasise is that 
classical liberalism recognises that states may have an important role to play within a liberal society. Just as hierarchical organisations such as firms may have efficiency advantages over smaller, more individualised production and consumption units in markets, so states or 'state-like' institutions may have comparative advantages when it comes to the maintenance of the rules needed to sustain a liberal order, such as protection of persons and property. The boundaries between those cases where action by state-like entities is required should not, however, be set in stone, but as with the boundaries of firms should be able to shift in response to technological and institutional innovations that enhance the relative effectiveness of alternatives. The ideal of the minimal state, therefore, is a relatively fluid one and does not represent an equilibrium point to which all efforts at institutional reform should be directed.

For classical liberals it is not the existence of state-like entities that should be questioned, but the processes through which these institutions may have arisen. The rules that govern the operation of markets may themselves emerge via a 'bottom-up' process of spontaneous order. In competitive sports, for example, individual teams voluntarily submit to the rules and regulations of particular 'leagues'. While teams compete for spectators and acclaim within such leagues, they also cooperate on dimensions that enhance the attractiveness of their particular league with respect to rivals within the same sport or indeed of competitor sports. Competition operates within a 'nested' structure - individuals and organisations compete against one another, but at a higher institutional level so do the standards and rules subscribed to by different groups of actors. Similarly, individuals and organisations may subscribe to institutional rules provided by states or state-like entities in order to secure advantages, such as greater security of property than might otherwise be available. States themselves meanwhile may subscribe to common norms and standards that may be enforced by supranational entities. Given the limits of human rationality and the possibility of self-interested action, what matters is whether the institutions concerned are arrived at via a process of consent rather than enforced coordination, and whether there is scope for dissenters to 'exit' at some level in order to subscribe to alternate practices.

In view of the 'knowledge problem' and recognition that 'incentives matter', the requirements of robust political economy represent a regulative standard against which to judge existing institutional practices and proposals for reform. The central tests of proposals for institutional reform should be whether they enhance the scope for evolutionary discovery and the extent to which they offer incentives that constrain the potentially oppressive powers of coercive authority. Many historical institutions, including states and supranational organisations, have resulted from monopolistic imposition rather than consensual evolution and may thus be the subject of critical scrutiny. 


\section{CHALLENGES TO CLASSICAL LIBERALISM AND THE STRUCTURE OF THE BOOK}

The principles outlined above aim to fulfil the criteria for a robust political economy of institutions and decisions. The claims advanced concerning the robustness of classical liberalism as a political project have not, however, gone without significant challenge and it is the purpose of this book to address some of the most significant objections in this regard. The book is structured in two parts. Part I examines the veracity of recent theoretical challenges to minimal state thinking that have emerged from the fields of economics and political theory. Part II then examines these questions in three areas of public policy that have proven most resistant to liberalisation.

\section{Part I: Challenges to Classical Liberalism}

The efficacy of markets in communicating information and generating productive incentives lies at the heart of the case for a framework of open markets and minimal government. The robustness of these arguments is, however, challenged by the 'new market failure' perspective of Joseph Stiglitz and his followers (Stiglitz, 1994). According to Stiglitz, while markets are a necessary component of a well-functioning economy, comparative institutional analysis does not imply support for classical liberalism but for a 'mixed economy' model. From a 'new market failure' perspective, markets are riddled with collective goods and asymmetric information problems which stifle the discovery and communication of information and which prevent the attainment of an efficient equilibrium. Consequently, widespread government action is deemed necessary to improve resource allocation via 'optimality taxes' and product regulation. More recently, this analysis has been reinforced by the path-dependency or network externalities approach of Paul David which argues for further intervention to correct 'market failures' in a wide range of areas afflicted with 'technological monopolies'.

Chapter 2 develops central themes from Hayek's economics and the Virginia school of public choice to argue that new market failure theory does not meet the requirements of robust political economy. On the one hand, this approach reduces comparative institutions analysis to issues of incentives. The 'knowledge problem' enunciated by Hayek is neglected by models that focus on incentives to search for information which is known in principle to be available. From a Hayekian perspective the function of markets is to alert people to unforeseen circumstances and opportunities, a function which cannot be analysed in terms of the equilibrium models central to neo-classical economics. Moreover, insofar as market failure theorists are right to focus on 'incentive compatibility', they fail to apply this analysis to their favoured 
institutional alternatives. A consistent analysis of collective action and asymmetric information problems reveals that these are often more pronounced in a public sector environment than they are in a regime of 'imperfect markets'.

Chapter 3 turns to critiques of classical liberalism from outside of economic theory. For communitarian political theorists such as Charles Taylor and the followers of Jurgen Habermas, the case for the market economy is based on assumptions of individual self-interest and the notion that 'incentives matter' (for example, Taylor, 1985; Habermas, 1992). These authors contend that classical liberalism neglects the social and moral context in which individual preferences are formed and is preoccupied with the pursuit of efficient 'means' rather than the discovery of new and more elevated 'ends'. A related set of arguments, considered in Chapter 4, claims that market processes and the principle of 'exit' undermine the moral and social capital on which they rely. Liberal economic policies are said to destroy cultural resources that emphasise solidarity and cooperation. According to each of these perspectives, therefore, markets need to be 'kept in their place' by an alternative set of institutions organised on 'voice-based' processes of deliberative democracy.

Communitarian political theory makes some telling points against 'hyperindividualist' and rationalistic forms of social science such as those found in the models of neo-classical economics. As Chapters 3 and 4 aim to show, however, even if one accepts all communitarian criticisms of neo-classical economics, none of these arguments proves effective against the case for a classical liberal regime. On the contrary, the arguments emphasised by Hayek suggest that markets and other 'exit'-based institutions may be better placed to facilitate the discovery of new tastes and values than democratic alternatives, because they allow greater scope for decentralised evolution. Similarly, attempts to sustain norms based on 'solidarity' through the use of government power, far from facilitating social unity may actually increase conflict. On each of these counts, therefore, communitarian arguments fail on their own terms. In addition, however, such theories lack any account of how democratic structures can deal with problems of inadequate incentives. While it is erroneous to assume that people always act out of self-interest, it is equally misguided to assume that democratic institutions are capable of transcending the importance of incentives. Judged by the standards of robust political economy, deliberative democracy may actually reduce the capacity for people to challenge and to question one another's ends, and far from building social capital may undermine adherence to cooperative social norms.

The final challenge to classical liberalism considered in Part I arises from egalitarian political theory. Shifts towards a more unequal distribution of wealth in societies that have undergone a process of economic liberalisation have prompted restatements of the claim that unfettered markets fail to satisfy the criteria of inclusion and social justice. Following Rawls (1971) and 
Dworkin (1981), philosophers in the liberal egalitarian tradition argue that income inequalities fail to deliver sufficient compensatory benefits to the worst-off and are incompatible with the principle of 'equality of respect'. For philosophers associated with recent theories of multiculturalism, meanwhile, these economic inequalities are only one component of a much wider range of exclusive social practices (in terms of gender, race and sexual identity) that are reinforced by private market processes (Young, 2000).

Chapter 5 examines the robustness of the egalitarian challenge in terms of the 'knowledge problem' and the 'incentive problem'. Given conditions of limited knowledge and the complex trade-offs pertinent to distributive justice, it argues that the principle of equal respect should not attempt to establish any one set of norms with regard to the distribution of income and social status. Rather, it should support a framework that enables individuals and voluntary associations to learn from a variety of distributive principles. Equality of respect, therefore, must be confined to the enforcement of the norms of 'noninterference' compatible with freedom of association and disassociation. In addition to these knowledge-based constraints, the chapter contends that theories of justice should not impose excessive 'strains of commitment' that fail to recognise the link between ownership and incentives. Within this context, egalitarian theories, which treat both personal talents and natural assets as 'common pool resources', are found to be incompatible with the principle that 'incentives matter'.

\section{Part II: Classical Liberalism and the Future of Public Policy}

Having offered a theoretical defence of classical liberalism in Part I, Part II examines some of these issues in more depth, focusing on three areas that have proven most resistant to liberalisation. Each of the chapters sets out a classical liberal agenda to the respective policy issues and then addresses objections derived from 'market failure' economics and both communitarian and egalitarian variants of political theory.

The first of the chapters in Part II deals with the question of poverty relief and the welfare state. Redistributive taxation and the provision of education and health care by the state have been sustained by arguments that suggest market processes are both inefficient and inequitable. Economists focus on informational problems that face service users, while for political theorists the concern is that markets undermine the 'public service' ethos and fail to provide adequate access or decision-making power to those on lower incomes. Chapter 6 shows, however, that while welfare state services do indeed provide informational problems for consumers, these tend to be exacerbated by government provision and regulation. With respect to ethical and political issues meanwhile, communitarian and egalitarian theories are shown to lack a robust 
account of why - even on their own terms - welfare state institutions should be judged superior to the mosaic of competing associations favoured by the classical liberal approach.

Chapter 7 focuses on the international dimension where much of the debate on 'neo-liberalism' is dominated by discussions over globalisation and trade. For critics, open market policies bring about increasing global inequalities owing to the intensification of competition between developed and developing nations. Drawing on 'path-dependency' theories, such critics support interventionist policies in developing nations combined with large-scale increases in economic assistance from wealthier countries in order to shift the trajectory of development in the poorest parts of the world. This analysis is reinforced by 'cosmopolitan' theories of justice, which argue that in a world of economic interdependence, questions of social or distributive justice should be extended beyond the nation state to encompass global democratic institutions. Chapter 7 questions the robustness of these contemporary development models, highlighting knowledge problems and incentive-based deficiencies in the case for global governance structures. It suggests that global aid agencies lack both the knowledge and incentives to choose an appropriate development path for lowincome countries, and contends that the pursuit of distributive justice is likely to empower global elites at the expense of citizens in both the developed and the developing world.

Chapter 8 turns to environmental policy, where most governments remain wedded to an approach that combines command and control regulation with centrally determined pricing schemes. This approach is premised on market failure theories that question the practicality of property rights solutions, and by those who argue that the moral status of environmental goods precludes their allocation on the basis of trade. Chapter 8 challenges these objections. It shows that while transaction costs surrounding the definition and enforcement of property rights provide obstacles to environmental markets, these costs obstruct social democratic processes to a far greater extent. In terms of ethics, the chapter shows that the case for establishing environmental property rights is not confined to arguments from efficiency, but is based on the view that market institutions allow the greatest scope for individuals and civil associations to express their commitments to environmental objectives over other values, including those of material prosperity. Finally, the chapter notes that although there is a class of 'global' environmental problems not readily amenable to robust classical liberal 'solutions', there is little reason to suppose on the grounds of either economics or ethics that centrally directed alternatives are any better suited to the issues in hand.

The book concludes in Chapter 9 with some alternative strategies for institutional reform. There is no one model of how to move towards a classical liberal regime of open markets and limited government. This will vary 
between countries, with the character of the evolutionary path affected by differences in the cultures and traditions concerned. What is crucial, however, is that policy-makers are equipped with a clear set of principles that should frame the direction of reform. It is the purpose of this book to articulate those principles. 